\title{
Rickets re-emerges in northern Aboriginal children
}

$\mathrm{D}$ ebate among researchers over the optimum dose of vitamin D is obscuring what one pediatrician calls a far more pressing problem: public health's "abysmal failure" to prevent a resurgence of rickets among Aboriginal children in Northern Canada and Alaska.

Doctors treating indigenous children in Nunavut, the Yukon, Northwest Territories and Alaska have seen growing numbers of cases of rickets over the last 20 years, two researchers told attendees at the International Meeting on Indigenous Child Health in Ottawa on Mar. 22.

"The abysmal failure to eradicate vitamin D-deficiency rickets, in my opinion, is far less about dosing recommendations," said Dr. Leanne Ward, director of Pediatric Bone Health Clinical and Research Programs at the Children's Hospital of Eastern Ontario in Ottawa. "As pediatric care providers and policymakers, our number one priority should be the prevention of rickets first."

Ward first sounded the alarm about rickets in Aboriginal children in the north in a 2007 CMAJ article. A survey of over 2300 pediatricians found there were 104 cases of children with rickets from 2002 to 2004, for an annual incidence rate of about 2.9 cases per 100000 in Canada. Between the ages of one and two years, the annual incidence of vitamin D-deficiency rickets for Canada as a whole was 12 per 100 000, added Ward. But in the Northwest Territories, Yukon Territory and Nunavut, the rates were 79,150 and 141 per 100000 respectively. So "the incidence of rickets was 6 to 12 times higher in these three regions compared to the rest of Canada, for children diagnosed between 1 and 2 years of age," Ward stated in an email.

"Those of us who are working in the trenches are seeing these children," Ward added.

In Alaska, the incidence from 2001 to 2010 was 4.2 cases per 100000 among native children, said Dr. Rachel

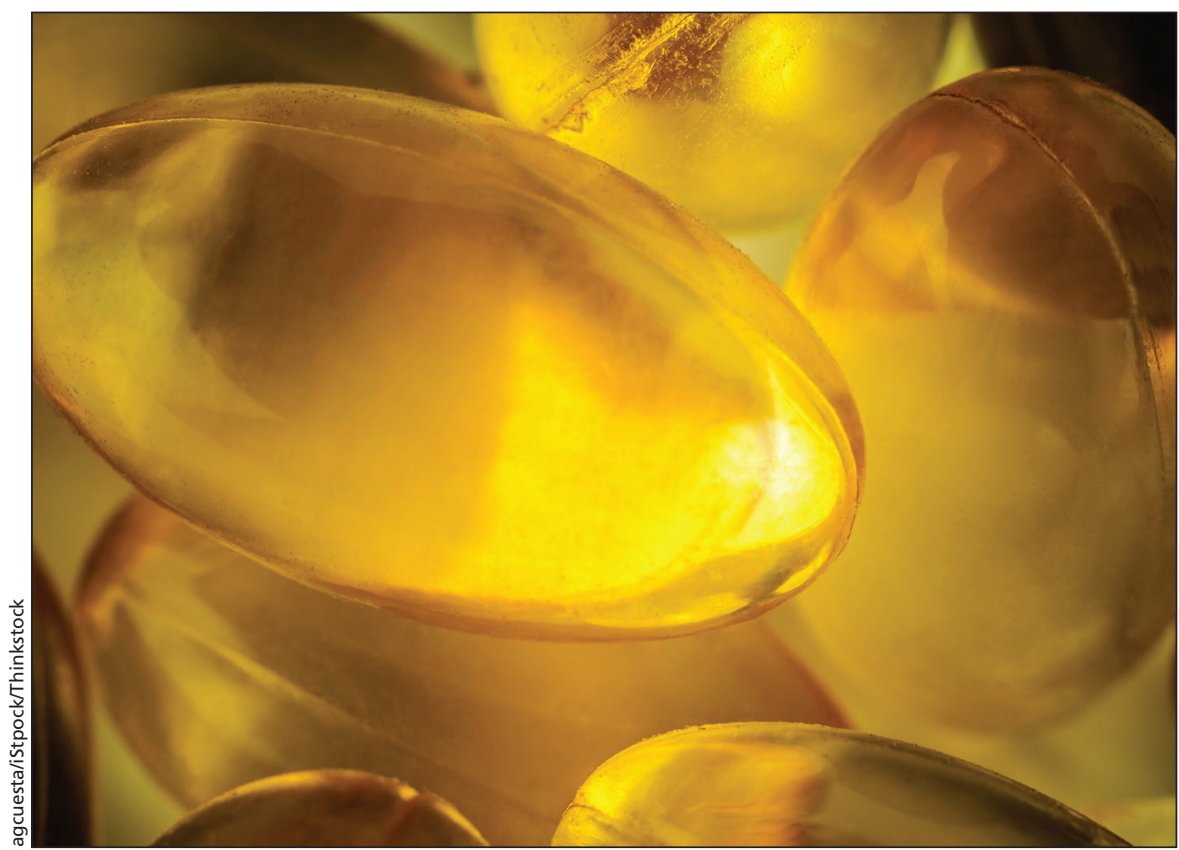

Vitamin D is available in traditional Aboriginal foods, but with the change in diet, rickets is an emerging problem.

Lescher, a pediatric endocrinologist with the Alaska Native Medical Center in Anchorage, who presented with Ward.

A report in the May 20, 2014, issue of State of Alaska Epidemiology Bulletin noted that 1999-2013 the incidence of rickets in Alaskan Native children increased 2.3-fold for every four-degree increase in latitude. And according to a case-control study, those who had rickets were 38 times more likely to have been malnourished.

Since Ward's 2007 paper, Lescher and northern Canadian doctors have continued to see children, including babies less than six months old, with severe symptoms. They include rickets' characteristic bowed legs and other skeletal deformities, fractures, failure to grow, delays in motor development, abnormalities in the heart muscle that can lead to heart failure, and life-threatening seizures caused by the body's inability to absorb calcium.

"It's not a benign disease that we're dealing with," said Lescher.

Rickets doesn't enter the minds of most parents living south of the 37th parallel. It's a disease more associated with the crippling legacy of poverty in Charles Dickens's England, and with his most famous character, Tiny Tim.

But for Aboriginal families in the north, rickets is a poorly understood risk. In addition to lack of sunlight, it is associated with food insecurity and the declining consumption of traditional or "country" foods, such as seal, salmon, bowhead or beluga whale, and caribou, which contains vitamin D.

Rickets is so rare in the south that it didn't even occur to Dr. Claudette Chase the first time she saw a child with bowed legs on a remote First Nation in Northwestern Ontario. When she referred her patient to a pediatrician in Winnipeg who had consulted widely in the North, he diagnosed it immediately. "I was shocked," says Chase.

Given the poverty and other conditions that have destroyed traditional practices such as feeding infants soup made from fish bones high in vita$\min \mathrm{D}$, Chase is no longer surprised by the re-emergence of rickets in the 23 First Nations communities where 
she practises, she says. But nurses and doctors new to the north, or at southern hospitals where northern women give birth, may not think to prescribe vitamin D.

Although health providers encourage breastfeeding, breast milk does not contain enough vitamin $\mathrm{D}$ to prevent rickets, and even babies bottle-fed with enriched formula are now showing up with deficiency, says Ward. That's why she recommends all babies in the North receive supplements.

Health care providers and the public need more education about the risks of vitamin $\mathrm{D}$ deficiency and about the importance of taking vitamin D daily, she says.

Since studies indicate many people don't take supplements even if they have them, she believes researchers should also conduct studies to test the safety of administering high doses of vitamin $\mathrm{D}$, either in one shot or intermittently. "We urgently need approaches that obviate the need for compliance and that focus on implementation." - Laura Eggertson, Ottawa, Ont.

CMAJ 2015. DOI:10.1503/cmaj.109-5027 